SINAI Journal of Applied Sciences

\title{
ASSESSMENT OF EGGPLANT (Solanum melongena L.) GENOTYPES UNDER NORTH SINAI CONDITIONS
}

\author{
Mahmoud I. Mahmoud and A.B. El-Mansy* \\ Dept. Plant Prod., Fac. Environ Agric. Sci., Arish Univ., Egypt.
}

\begin{abstract}
The present investigation aimed to assess twenty genotypes of eggplant under open field conditions of El-Arish region during two seasons (2016 and 2017) at the Experimental Farm, Faculty of Environmental Agricultural Sciences, Arish University. The evaluation was conducted using a randomized complete block design in three replications. Results of mean performance showed highly significant differences among genotypes for all traits, the best lines were Jor-2 for early flowering, PIG-4 for both early and total yield (kg/plant) and Spa-3 for average fruit weight (g). Estimation of phenotypic coefficient of variation (PCV) was higher than genotypic coefficient of variation (GCV) for all traits. However, close estimates of GCV and PCV indicated that genetic variance contributed with large portion in phenotypic expression of most characters. Therefore, phenotypic selection is effective and suitable for improvement. The genotypic (GCV) and phenotypic (PCV) coefficients of variation were moderate for plant height, early yield/plant, total yield and fruit firmness. On the other hand, estimations were high for number of branches/plant, average fruit weight, fruit length, fruit diameter and TSS (\%), indicating sufficient genetic variability for these traits and so, genetic improvement through selection is effective. Heritability estimates in broad sense were high for early yield/plant, total yield /plant, average fruit weight, fruit length, fruit diameter and TSS (\%). High heritability accompanied with high GAM were found for early yield/plant, total yield/plant, average fruit weight, fruit length, fruit diameter and TSS (\%), suggesting preponderance of additive gene action and improvement through selection is effective. The genetic divergence based on Euclidean distance among twenty genotypes were grouped into five divergent clusters. The pattern of distribution showed that cluster 5 involved the largest number (nine lines), followed by cluster 1 (consisted of six lines) and cluster 4 (included three lines). While, both clusters 2 and 3 involved one genotype. Cluster means showed that first cluster gave high performance for only fruit firmness, second cluster recorded the highest mean values for total yield /plant, fruit length and TSS (\%). also, third cluster produced the highest mean value for plant height, early yield/plant, average fruit weight and fruit diameter. However, fourth cluster exhibited maximum values for number of branches/plant and early flowering. So, more emphasis should be given on clusters 1, 2, 3 and 4 for choosing parents for crossing which may produce new recombinants with desired economic traits.
\end{abstract}

Key words: Eggplant, variability, heritability, genetic advance, genetic divergence

\section{INTRODUCTION}

Eggplant (Solanum melongena L.) is one of major vegetables grown and consumed in Egypt. It is rich in vitamins like thiamine, niacin, and folacin as well as essential minerals like $\mathrm{Ca}, \mathrm{Fe}, \mathrm{K}, \mathrm{Zn}, \mathrm{Cu}$ and Mn (Kowalski et al., 2003). In Egypt yield potentiality of cultivated varieties is less and choice of eggplant size, shape, and skin colour varies in different locations. For developing eggplant varieties with high

\footnotetext{
* Corresponding author: Tel.: +201211343842

E-mail address: aelmansy@aru.edu.eg
} 
productivity, colour, and environmental resistances, there is require for systemic breeding plane. Evaluation for most important traits help to collect information for development of the crop, also provide breeders with row picture of genotypes about genetic variability and diversity. Therefore, evaluation of germplasm is mandatory to understand the genetic background and calculate the breeding value of available germplasm and determined the best genotypes in concern to economic traits.

Variability is urgently needed for ultimate use in any crop improvement. Greater extent of variability in population, greater chance for effective selection (Vavilov, 1951). Success of selection is depend upon existing and magnitude of genetic variability. So, it is necessary to partition total variability to principal components (heritable and non-heritable) through estimation of some genetic parameters like phenotypic (PCV) and genotypic (GCV) coefficient of variability, heritability and genetic advance that gave complete indication of genetic variations of the studied traits.

Correlation analysis measure the relationship between any pairs of traits and determines the component characters that selection can be based for improvement the economic traits. Plant height was positively correlated with average fruit weight (Muniappan et al., 2010; Prabakaran et al., 2015), total yield/plant (Nair and Mehta, 2007; Muniappan et al., 2010; Shekar et al., 2014; Ullah et al., 2014), Fruit diameter (Shekar et al., 2014) and Fruit length (Muniappan et al., 2010). Also, significant positive correlations were found between number of branches and total fruit weight (Tripathy et al., 2018). Days to first flower anthesis positively correlated with fruit length (Danquah and Ofori, 2012; Shekar et al., 2014; Prabakaran et al., 2015), fruit diameter (Prabakaran et al., 2015), average fruit weight (Prabakaran et al., 2015). Tripathy et al. (2018) showed significant positive correlation between TSS (\%) and total yield/plant.

Genetic diversity in crops help breeders to exclude some genotypes that closely related and concerted their efforts on distant genotypes. Mahalanobis $\mathrm{D}^{2}$ is the method developed to assessing genetic divergence among accessions. Also, grouping genotypes in differ clusters will be more useful to identifying the better parents for the hybridization program. Many investigators studied genetic diversity in eggplant among them Begum et al. (2013), Kumar and Arumugam (2013), Shekar et al. (2014) and Nand et al. (2018). Genetic variability and diversity of eggplant for six yield contributed characters were studied by Ullah et al. (2014), where they found that cluster analysis divided the lines to 3 clusters, as well as genotypes involved in cluster one showed high genetic distant for some important traits, so selection is effective in this cluster. Genetic divergence among 40 genotypes of eggplant was estimated by Yadav et al. (2017), based on qualitative and quantitative traits, they divided the genotypes to seven clusters. Also, based on 19 traits using Mahalanobis $\mathrm{D}^{2}$ method, Ravali et al. (2017) divided 35 genotypes of eggplant into 10 clusters. Therefore, the present study was undertaken to assessment twenty genotypes of eggplant for vegetative growth, yield and fruit quality, as well as estimate genetic parameters, correlation and genetic diversity to select the superior genotypes for future use.

\section{MATERIALS AND METHODS}

Twenty genotypes of eggplant were collected and evaluated under open field conditions at the Experimental Farm, Faculty of Environmental Agricultural Sciences, Arish University, Egypt, during two seasons 2016 and 2017. Fifteen genotypes (Jor-1, Jor-2, Jor-3, Jor-4, Jor-5, 
Spa-1, Spa-2, Spa-3, Spa-4, Spa-5, Spa-6, L-W, S2-1, Mashor and Black Beauty (B1B)) were obtained from Prof. Dr. ElMahdy Ibrahim Metwally, Prof. of Vege. Crops, Hort. Dept., Fac. Agric. Kafr El-Sheikh Univ. The remaining genotypes (PIG-3, PIG-4, PIG-13, PIG-14 and PIG15) were obtained from Prof. Dr. Abd ElMoniem A. Gad, Prof. Veg. Crops, Dept. Hort., Fac. Agric., Zagazig Univ., "Classic $\mathrm{F}_{1 "}$ (Tezier Com.) was used as a check.

The experimental design used was a randomized complete block design with three replications. Each replicate contained 21 experimental unit. Each plot was a single row (10 m length and $1 \mathrm{~m}$ width), therefore, the plot area was $10 \mathrm{~m}^{2}$. The distance between plants was $50 \mathrm{~cm}$ apart. In both seasons, seeds genotypes were sown on January $15^{\text {th }}$ in seedling trays and the seedlings were transplanted on March $15^{\text {th }}$. Fertigation program was carried out according to recommendations under drip irrigation system.

After four months, five plants from each experimental unit were randomly chosen to determine the following vegetative traits, plant height $(\mathrm{cm})$ and number of branches/ plant. Days to first flower anthesis was calculated. Early yield/ plant was calculated from the first three harvestings, also total yield/plant was calculated from all harvested fruits.

Average fruit weight (g), was determined by dividing total yield on total fruit number. Five fruits from each plot were taken at ripe stage from the fourth harvest to determine fruit length $(\mathrm{cm})$, fruit diameter $(\mathrm{cm})$, TSS $(\%)$, Fruit firmness $\left(\mathrm{kg} / \mathrm{cm}^{2}\right)$ and fruit colour at the marketable stage.

Average data over two seasons (2016 and 2017) were calculated and subjected to statistical procedures to the analysis of variance for a randomized complete block design as outlined by Cochran and Cox (1957), and means separation was done according to Duncan (1955). Genotypic coefficient of variation (GCV) and phenotypic coefficient of variation (PCV) were calculated according to Burton and Devane (1953), heritability in broad sense was estimated according to Allard (1960). Genetic advance and genetic advance as percent of mean were calculated using the formula of Johnson et al. (1955). Phenotypic (rph) and genotypic (rg) correlations among pairs of studied traits were made as outlined by Steel and Torrie (1980). Genetic diversity between genotypes was estimated by the method of Mahalanobis $\mathrm{D}^{2}$ statistics (Mahalanobis, 1936) using statistical software program SPSS $^{\text {v.18. }}$

\section{RESULTS AND DISCUSSION}

\section{Mean performance}

Mean performance results for twentyone genotypes revealed highly significant differences among them, indicating presence of enormous amount of variability for all characters (Table 1). For plant height, values varied from 89.0 to 124.7 cm, among 20 genotypes, Spa- 6 recorded the maximum value. All evaluated genotypes, except four ones exceeded significantly the check hybrid (Classic $\mathrm{F}_{1}$ ). Eight genotypes gave values higher than the grand mean (104.6). Five genotypes (Jor-3, Jor-5, Spa-1, Spa-3 and Spa-4) gave the highest number of branches/plant $(6.3,7.0$, $7.7,6.7$ and 7.0, respectively) without significant differences among them, while, eleven genotypes exhibited significantly higher number of branches compared to check hybrid (4.0). Nine lines exceeded the overall mean of this trait (5.2).

For days to first flower anthesis, the line Jor-2 was as earlier (28.3), followed by Jor3 (30.7) and Spa-6 (30.7), while PIG-13 took the maximum days (41.0). Eight genotypes recorded less number of days compared to overall mean. 
Early yield/plant ranged from $0.121 \mathrm{~kg}$ to $0.251 \mathrm{~kg}$, with overall mean $0.189 \mathrm{~kg}$. Only genotype (PIG-4) exceeded the check hybrid (Classic $\left.\mathrm{F}_{1}\right)(0.221 \mathrm{~kg})$, however seven ones did not differ than the check hybrid. Total yield $\mathrm{kg} /$ plant of evaluated genotypes showed differences ranged from 1.4 to $2.2 \mathrm{~kg}$. The highest yield was reflected by PIG-4 (2.2 kg), followed by Spa-6 (2.12 kg), and Mashor (2.1 kg). On the other hand, nine lines produced total yield/plant higher than the grand mean (1.84 kg).

The line Spa-3 produced the heaviest fruits $(182 \mathrm{~g})$, followed by both of Spa-1 (157 g) and Spa-4 (159 g), while both of Spa-2 and PIG-3 gave the lightest fruits (67 and $66 \mathrm{~g}$, respectively), three lines significantly exceeded (classic $\mathrm{F}_{1}$ ) (137 g), as well as six ones did not differ than the check hybrid. The mean fruit length was found to be highest in PIG-14 $(27.67 \mathrm{~cm})$ and lowest in Spa-3 $(11.33 \mathrm{~cm})$. Seven lines gave longer fruits than the grand mean $(17.52 \mathrm{~cm})$, also all evaluated genotypes, except three ones (Spa-3, Spa-4 and BL-B) exceeded significantly the classic $\mathrm{F}_{1}(12.77$ $\mathrm{cm})$. Fruit diameter among evaluated genotypes ranged from $3.67 \mathrm{~cm}$ (Jor-2) to $16.50 \mathrm{~cm}$ (Jor-4) with a grand mean of 8.62 $\mathrm{cm}$, indicating wide variation among studied genotypes for this trait. Most evaluated lines had wider fruits compared to check hybrid $(5.33 \mathrm{~cm})$ which produce cylindrical fruits. Results of fruit length and diameter showed differ fruit shaped (round, longer and cylindrical) among lines.

Table 1. Mean performance of eggplant genotypes for different yield component and biochemical characters over two seasons (2016 and 2017).

\begin{tabular}{|c|c|c|c|c|c|c|c|c|c|c|c|}
\hline Genotypes & $\begin{array}{l}\text { Plant } \\
\text { height } \\
(\mathrm{cm})\end{array}$ & \begin{tabular}{|c|} 
No. of \\
branches/plant
\end{tabular} & $\begin{array}{c}\text { Days to } \\
\text { first flower } \\
\text { anthesis }\end{array}$ & $\begin{array}{l}\text { Early yield } \\
\text { (Kg/plant) }\end{array}$ & $\begin{array}{l}\text { Total yield } \\
\text { (Kg/plant) }\end{array}$ & $\begin{array}{c}\text { Average fruit } \\
\text { Wight } \\
\text { (g/plant) }\end{array}$ & $\begin{array}{l}\text { Fruit length } \\
\quad \text { (cm) }\end{array}$ & $\begin{array}{c}\text { Fruit } \\
\text { diameter } \\
(\mathrm{cm})\end{array}$ & TSS (\%) & $\begin{array}{c}\text { Fruit firmness } \\
\left(\mathrm{kg} / \mathrm{cm}^{2}\right)\end{array}$ & Fruit colour \\
\hline Jor-1 & 97.33 DE & $4.33 \mathrm{D}$ & 33.67 BC & $0.230 \mathrm{~B}$ & $2.07 \mathrm{D}$ & 129.38 CD & 17.83 D & $10.17 \mathrm{E}$ & $6.83 \mathrm{~B}$ & $2.467 \mathrm{HM}$ & Black \\
\hline Jor-2 & $100.0 \mathrm{CDE}$ & $5.00 \mathrm{CD}$ & 28.33 E & $0.151 \mathrm{GH}$ & $1.80 \mathrm{~K}$ & $85.714 \mathrm{HI}$ & 15.33 EF & $3.67 \mathrm{M}$ & $5.83 \mathrm{C}$ & 3.033 E-H & Black \\
\hline Jor-3 & 101.3 CDE & $6.33 \mathrm{ABC}$ & 30.67 D & 0.181 E & $1.90 \mathrm{H}$ & 95 GH & 14.00 FG & $9.50 \mathrm{E}$ & $6.83 \mathrm{~B}$ & 3.200 C-G & Purple \\
\hline Jor-4 & 95.00 DE & $5.33 \mathrm{BCD}$ & $34.00 \mathrm{BC}$ & $0.201 \mathrm{D}$ & $1.40 \mathrm{Q}$ & 117.7 DEF & $15.50 \mathrm{EF}$ & $16.50 \mathrm{~A}$ & 4.17 EF & $2.80 \mathrm{GH}$ & Black \\
\hline Jor-5 & $92.00 \mathrm{E}$ & $7.00 \mathrm{~A}$ & $34.00 \mathrm{BC}$ & $0.211 B C D$ & $1.80 \mathrm{~K}$ & $138.46 \mathrm{C}$ & $14.00 \mathrm{FG}$ & $14.33 \mathrm{~B}$ & 5.50 CD & $3.47 \mathrm{~B}-\mathrm{F}$ & Black \\
\hline Spa-1 & 101.0 CDE & $7.67 \mathrm{~A}$ & 33.67 BC & $0.213 B C D$ & $1.73 \mathrm{M}$ & 157.27 B & 14.00 FG & $13.00 \mathrm{C}$ & 4.17 EF & 3.87 ABC & Dark purple \\
\hline Spa-2 & 89.00 E & 5.33 BCD & $34.00 \mathrm{BC}$ & 0.181 E & $1.60 \mathrm{O}$ & $66.67 \mathrm{~J}$ & 14.00 FG & $9.17 \mathrm{EF}$ & $4.17 \mathrm{EF}$ & $3.97 \mathrm{AB}$ & Purplish white \\
\hline Spa-3 & $93.00 \mathrm{E}$ & $6.67 \mathrm{AB}$ & 35.33 B & $0.221 \mathrm{BC}$ & $1.82 \mathrm{~J}$ & 182.1 A & $11.33 \mathrm{H}$ & $11.83 \mathrm{D}$ & $5.00 \mathrm{D}$ & 3.57 B-F & Dark purple \\
\hline Spa-4 & 95.33 DE & $7.00 \mathrm{~A}$ & 35.33 B & $0.211 \mathrm{CD}$ & $1.75 \mathrm{~L}$ & 159.27 B & 13.00 GH & $10.17 \mathrm{E}$ & $8.33 \mathrm{~A}$ & 3.03 E-H & Light green \\
\hline Spa-5 & 95.00 DE & $3.67 \mathrm{D}$ & 34.33 BC & $0.141 \mathrm{HI}$ & $1.79 \mathrm{~K}$ & 105 EFG & 16.67 DE & $7.67 \mathrm{GH}$ & $4.83 \mathrm{DE}$ & $3.47 \mathrm{~B}-\mathrm{F}$ & Black \\
\hline Spa-6 & 124.7 A & $4.33 \mathrm{D}$ & 30.67 D & 0.169 EF & $2.12 \mathrm{~B}$ & 112D-G & 23.33 B & $5.17 \mathrm{KL}$ & 4.17 EF & $4.267 \mathrm{~A}$ & Purple \\
\hline L-W & $108.3 \mathrm{BCD}$ & $5.00 \mathrm{CD}$ & 33.33 BC & 0.161 FG & $1.91 \mathrm{GH}$ & $120 \mathrm{CDE}$ & 23.67 B & 6.17 JK & $7.00 \mathrm{~B}$ & $2.80 \mathrm{GH}$ & White \\
\hline S2-1 & $111.7 \mathrm{ABC}$ & $4.00 \mathrm{D}$ & 34.00 BC & $0.212 B C D$ & $2.00 \mathrm{~F}$ & 118 DEF & 18.33 D & 8.50 FG & 4.13 EF & 3.77 CD & Purple \\
\hline Mashor & 118.0 AB & $4.67 \mathrm{D}$ & 32.00 CD & 0.129 IJ & $2.10 \mathrm{C}$ & 100 FGH & $20.33 \mathrm{C}$ & $4.67 \mathrm{~L}$ & $5.00 \mathrm{D}$ & 2.93 FGH & Black \\
\hline PIG-3 & $116.7 \mathrm{AB}$ & $5.33 \mathrm{BCD}$ & $34.00 \mathrm{BC}$ & $0.151 \mathrm{GH}$ & $1.72 \mathrm{M}$ & $66 \mathrm{~J}$ & 22.67 B & $6.67 \mathrm{IJ}$ & $6.83 \mathrm{~B}$ & $3.80 \mathrm{~A}-\mathrm{D}$ & Purple \\
\hline PIG-4 & $91.00 \mathrm{E}$ & $4.33 \mathrm{D}$ & 35.33 B & $0.251 \mathrm{~A}$ & $2.20 \mathrm{~A}$ & 105 EFG & 16.83 DE & $7.17 \mathrm{HI}$ & $5.83 \mathrm{C}$ & 3.73 A-D & White \\
\hline PIG-13 & 101.0 CDE & $4.33 \mathrm{D}$ & $41.00 \mathrm{~A}$ & $0.121 \mathrm{~J}$ & $1.63 \mathrm{~N}$ & $74 \mathrm{IJ}$ & $15.33 \mathrm{EF}$ & 8.50 FG & 3.50 FG & 3.63 A-E & Black \\
\hline PIG-14 & $120.0 \mathrm{AB}$ & $4.33 \mathrm{D}$ & $34.00 \mathrm{BC}$ & $0.219 \mathrm{BC}$ & $1.92 \mathrm{G}$ & $128 \mathrm{CD}$ & $27.67 \mathrm{~A}$ & $4.63 \mathrm{~L}$ & $6.83 \mathrm{~B}$ & 3.63 A-E & Black \\
\hline PIG-15 & $121.7 \mathrm{AB}$ & 5.33 BCD & $35.00 \mathrm{~B}$ & 0.222 BC & $1.87 \mathrm{I}$ & $125 \mathrm{CD}$ & 13.50 FG & $12.83 \mathrm{C}$ & $6.83 \mathrm{~B}$ & 3.367B-G & Black \\
\hline BL-B & $119.0 \mathrm{AB}$ & $3.67 \mathrm{D}$ & 32.33 CD & $0.201 \mathrm{D}$ & $1.51 \mathrm{P}$ & $137 \mathrm{C}$ & 13.00 GH & $12.9 \mathrm{C}$ & $4.17 \mathrm{EF}$ & $4.033 \mathrm{AB}$ & Black \\
\hline Classic & 87.33 E & $4.00 \mathrm{D}$ & 33.33 BC & $0.221 \mathrm{BC}$ & $2.05 \mathrm{E}$ & $137 \mathrm{C}$ & 12.77 GH & $5.33 \mathrm{KL}$ & $3.00 \mathrm{G}$ & 3.13 D-G & Black \\
\hline $\mathbf{X}^{-}$ & 103.73 & 5.13 & 33.73 & 0.19 & 1.84 & 116.96 & 17.29 & 8.62 & 5.38 & 3.43 & \\
\hline
\end{tabular}


Means followed by the same alphabetical letter(s) within each column are not significantly different at 5\% level according to Duncan's Multiple Range Test.

Total soluble solids percentage (TSS\%) varied from 3.5 (PIG-13) to 8.3 (Spa-4). The highest TSS (\%) was recorded by Spa4 followed by Jor-1, Jor-3, L-W, PIG-3, PIG-14 and PIG-15. All evaluated lines exceeded (Classic $\left.\mathrm{F}_{1}\right)(3.0 \%)$, while, ten ones exhibited high TSS (\%) than the grand mean $(5.38 \%)$. Highly variations were observed among genotypes for fruit firmness which ranged from 2.467 to 4.267 $\mathrm{kg} / \mathrm{cm}^{2}$. The highest hardness fruits were found in Spa-1, Spa-2, Spa-6, S2-1, PIG-3, PIG-4, PIG-13, PIG-14 and PIG-15 without significant differences among them. Fourteen lines significantly produced hardness fruits than the check (Classic $F_{1}$ ) $\left(3.13 \mathrm{~kg} / \mathrm{cm}^{2}\right)$.

Regarding fruit colour at marketable stage, the studied genotypes showed wide range of colour variations. The genotypes divided into the following groups: first group (black) included Jor-1, Jor-2, Jor-4, Jor-5, Spa-5, Mashor, PIG-13, PIG-14,
PIG-15 and BL-B; the second group (white colour) involved L-W and PIG-4. The third group (purplish white) included only line Spa-2. The fourth group included six lines with fruits of purple colour (Jor-3, Spa-1, Spa-3, Spa-6, S2-1 and PIG-3); the fifth group gave fruits with light green colour (Spa-4). These variations enable the breeders to choose parents with different colours to produce high suitable hybrids to consumers. These results agree with those of Nair and Mehta (2007), Kansouh and Hussein (2009), Shekar et al. (2014), Prabakaran et al. (2015) and Samlindsujin et al. (2017) who found significant variations among evaluated genotypes of eggplant for studied characters.

\section{Genetic variability}

Genetic variability as genotypic coefficient of variation (GCV), phenotypic coefficient of variation (PCV), heritability in broad sense (HB), genetic advance (GA) and genetic advance as percent of mean (GAM) for ten studied characters are presented in Table 2.

Table 2. Genetic variability parameters for different yield components and biochemical characters of eggplant over two seasons.

\begin{tabular}{|c|c|c|c|c|c|}
\hline Character & $\begin{array}{c}\text { GCV } \\
(\%)\end{array}$ & $\begin{array}{r}\text { PCV } \\
(\%)\end{array}$ & $\begin{array}{c}\text { Heritability } \\
\left(\mathbf{h}^{2} \%\right)\end{array}$ & $\begin{array}{c}\text { Genetic } \\
\text { Advance } \\
\text { (GA) }\end{array}$ & $\begin{array}{c}\text { Genetic } \\
\text { Advance } \\
\text { (\% of Mean) }\end{array}$ \\
\hline 1- Plant height & 10.89 & 12.99 & 70.23 & 19.499 & 18.798 \\
\hline 2-Number of branches/plant & 20.87 & 26.59 & 61.63 & 1.731 & 33.758 \\
\hline 3- Days to first flower anthesis & 6.78 & 7.83 & 74.98 & 4.078 & 12.089 \\
\hline 4- Early yield (Kg/plant) & 18.92 & 19.64 & 92.86 & 0.072 & 37.562 \\
\hline 5- Total yield (Kg/plant) & 11.25 & 11.2 & 99.77 & 0.427 & 23.146 \\
\hline 6- Average fruit Wight (g/plant) & 25.84 & 25.84 & 99.98 & 62.264 & 53.234 \\
\hline 7- Fruit length $\left(\mathrm{cm}^{2}\right)$ & 25.60 & 26.44 & 93.73 & 8.827 & 51.049 \\
\hline 8- Fruit diameter $\left(\mathrm{cm}^{2}\right)$ & 40.88 & 41.41 & 97.43 & 7.162 & 83.115 \\
\hline 9- TSS (\%) & 26.25 & 27.36 & 92.10 & 2.792 & 51.905 \\
\hline 10- Fruit firmness $\left(\mathrm{kg} / \mathrm{cm}^{2}\right)$ & 12.43 & 15.99 & 60.38 & 0.682 & 19.889 \\
\hline
\end{tabular}


All studied traits showed wide range of variability as evident from determined genetic parameters, this providing the ample scope for selecting best genotypes. Estimation of PCV was higher than GCV in all traits, indicating influence of environmental factors. However, close estimates of GCV and PCV indicated that genetic variance contributed with large portion in phenotypic expression rather than environmental factors of most characters. Therefore, phenotypic selection is effective and suitable for improvement. Similar findings on eggplant were found by many researchers, among them, Kumar et al. (2012), Kumar and Arumugam (2013), Yadav et al. (2016) and Pujer et al. (2017).

The genotypic (GCV) and phenotypic (PCV) coefficients of variation were moderate for plant height (10.89 and 12.99), early yield/plant (18.92 and 19.64), total yield (11.25 and 11.2) and fruit firmness (12.43 and 15.99), respectively, indicated presence of moderate genotypic variation and improvement through selection are suitable for these characters. On the other hand, estimation of genotypic (GCV) and phenotypic (PCV) coefficients of variation were high for number of branches/plant (20.87 and 26.59), average fruit weight (25.84 and 25.84), fruit length (25.60 and 26.44), fruit diameter (40.88 and 41.41) and TSS (\%) (26.25 and 27.36), respectively, suggesting sufficient genetic variability for these traits, so, genetic improvement through selection is effective. However, the estimated values of GCV and PCV were low for days to first flower anthesis $(6.78$ and 7.83 , respectively) indicating less effect of genetic variability in this trait and selection might be not effective. These results, were confirmed by many researchers among them, Islam and Uddin (2009) and Kumar et al. (2012) both for days to first flower anthesis, Yadav et al. (2016) for fruit length and diameter, Samlindsujin et al. (2017) for plant height, number of branches, average fruit weight and total yield/plant, and Tirkey et al. (2018) for TSS (\%) .

Heritability estimates in broad sense were high for early yield /plant, total yield/ plant, average fruit weight, fruit length, fruit diameter and TSS (\%) (92.86, 99.77, 99.98, 93.73, 97.43 and 92.10, respectively) (Table 2), indicating less environment effects on the phenotypic expression of these traits. So, selection based on phenotypic observation in individual plant is more effective to improve of these characters, while, it was moderate for the remaining traits (plant height, number of branches/plant, days to first flower anthesis and fruit firmness), therefore, these traits might be improved by selection. This result was in conformity with the findings of Ansari et al. (2011), Rad et al. (2015) and Pujer et al. (2017) who evaluated many genotypes of eggplant and found that selection is effective in the improvement of these traits.

Genetic advance (GA) help plant breeders to predict genetic gain that obtained in late generations of the breeding program. The values of genetic advance exhibited wide range from 0.071 for early yield/plant to 62.26 for average fruit weight (Table 2). However, genetic advance as percent of mean (GAM) varied from trait to another, it was high for, number of branches (33.76), early yield/plant (37.56), total yield/plant (23.45), average fruit weight (53.23), fruit length (51.05), fruit diameter (83.11) and TSS (\%) (51.91), indicating that these traits are governed by additive gene action and selection will be effective in improvement of these traits. however, the remaining traits (plant height, days to first flower anthesis and fruit firmness) showed moderate values of GAM (18.80, 12.09 and 19.89, respectively).

Heritability associated with genetic advance as percent of mean (GAM) is more important in predicting the results and 
effect of selection. High heritability correlated with high GAM were found in early yield/plant, total yield/plant, average fruit weight, fruit length, fruit diameter and TSS (\%), indicated the preponderance of additive gene action in the inheritance of these characters and that improvement through selection is effective. Similarly, moderate heritability coupled with high GAM gave the same way for improving number of branches/plant. On the other hand, moderate heritability associated with moderate GAM were noticed in plant height, days to first flower anthesis and fruit firmness, indicating predominance of additive gene effects and selection as breeding strategy might be effective to improve these traits. In this concern, high heritability associated with moderate and/or high GAM was also reported by Yadav et al. (2016), Samlindsujin et al. (2017), Pujer et al. (2017) and Tirkey et al. (2018).

\section{Correlations}

The genotypic (rg) and phenotypic correlation coefficients (rph) among ten traits of eggplant were calculated and presented in Table 3. Correlation help in identifying characters that have little or no importance in the selection improvement programs. In general, genotypic correlations were higher than that of phenotypic ones for most traits, this might be due to the strong inherent genetic relationship between the studied characters and masking effect of environmental factors.

Highly significant positive correlations were observed between plant height and all studied traits, except fruit diameter. Similar results were obtained by Nair and Mehta (2007), Shende et al. (2014) both for total yield/plant, Muniappan et al. (2010) for yield/plant, fruit length and weight.

Table 3. Phenotypic (rph) and genotypic (rg) correlation coefficients among 10 characters of eggplant grown over two seasons (2016 and 2017).

\begin{tabular}{|c|c|c|c|c|c|c|c|c|c|c|}
\hline & & 2 & 3 & 4 & 5 & 6 & 7 & 8 & 9 & 10 \\
\hline \multirow[t]{2}{*}{ 1- Plant highte } & $\mathrm{rph}$ & $0.511 *$ & $0.806^{* *}$ & $0.583 * *$ & $0.816^{* *}$ & $0.526^{*}$ & $0.829 * *$ & 0.258 & $0.618 * *$ & $0.819 * *$ \\
\hline & rg & $0.589 * *$ & $0.836 * *$ & $0.576 * *$ & $0.833 * *$ & $0.513 *$ & $0.868 * *$ & 0.338 & $0.695 * *$ & $0.866 * *$ \\
\hline \multirow[t]{2}{*}{ 2- Number of branches } & rph & & $0.658 * *$ & $0.613 * *$ & $0.531 * *$ & $0.665 * *$ & 0.164 & $0.721 * *$ & $0.609 * *$ & $0.561 * *$ \\
\hline & $\mathrm{rg}$ & & $0.729 * *$ & $0.652 * *$ & $0.585 * *$ & $0.696 * *$ & 0.254 & $0.787 * *$ & $0.688 * *$ & $0.635^{* *}$ \\
\hline \multirow[t]{2}{*}{3 - Days to first flower anthesis } & $\mathrm{rph}$ & & & $0.723 * *$ & $0.813 * *$ & $0.624 * *$ & $0.562 * *$ & $0.542 * *$ & $0.575 * *$ & $0.823 * *$ \\
\hline & rg & & & $0.696 * *$ & $0.803 * *$ & $0.591 * *$ & $0.611 * *$ & $0.607 * *$ & $0.658 * *$ & $0.853 * *$ \\
\hline \multirow[t]{2}{*}{ 4- Early yield/plant } & $\mathrm{rph}$ & & & & $0.722 * *$ & $0.798 * *$ & 0.365 & $0.581 * *$ & $0.548 * *$ & $0.640 * *$ \\
\hline & rg & & & & $0.686 * *$ & $0.777 * *$ & 0.385 & $0.626 * *$ & $0.597 * *$ & $0.637 * *$ \\
\hline \multirow[t]{2}{*}{ 5- Total yield/plant } & $\mathrm{rph}$ & & & & & $0.599 * *$ & $0.634 * *$ & 0.249 & $0.627 * *$ & $0.728 * *$ \\
\hline & $\mathrm{rg}$ & & & & & $0.553 * *$ & $0.678 * *$ & 0.305 & $0.702 * *$ & $0.745^{* *}$ \\
\hline \multirow[t]{2}{*}{ 6- Average fruit wight } & $\mathrm{rph}$ & & & & & & 0.288 & $0.545 * *$ & $0.455 *$ & $0.502 *$ \\
\hline & $\mathrm{rg}$ & & & & & & 0.299 & $0.577 * *$ & $0.490 *$ & $0.488 *$ \\
\hline \multirow[t]{2}{*}{ 7- Fruit length } & $\mathrm{rph}$ & & & & & & & -0.094 & $0.502 *$ & $0.625 * *$ \\
\hline & $\mathrm{rg}$ & & & & & & & 0.002 & $0.570 * *$ & $0.685 * *$ \\
\hline \multirow[t]{2}{*}{ 8- Fruit diameter } & $\mathrm{rph}$ & & & & & & & & 0.305 & 0.325 \\
\hline & $\mathrm{rg}$ & & & & & & & & 0.380 & 0.397 \\
\hline \multirow[t]{2}{*}{ 9- TSS (\%) } & $\mathrm{rph}$ & & & & & & & & & 0.373 \\
\hline & rg & & & & & & & & & $0.469 *$ \\
\hline
\end{tabular}

*and **means significant and highly significant at $0.05,0.01$ level of probability, respectively. 
Also, number of branches/plant, was highly significantly positive correlated with days to first flower anthesis, early yield/ plant, total yield/plant, average fruit weight, fruit diameter, TSS (\%) and fruit firmness. Similar finding was reported by Tripathy et al. (2018) for total yield/plant.

In addition, highly significant positive correlations were found between days to first flower anthesis and early yield/plant, total yield/plant, average fruit weight, fruit length, fruit diameter, TSS (\%) and fruit firmness. Danquah and Ofori (2012) and Shekar et al. (2014) found similar results for fruit length, Prabakaran et al. (2015) for fruit length, diameter and fruit weight

Highly significant positive relations were detected between early yield/plant and total yield/plant, average fruit weight, fruit diameter, TSS (\%) and fruit firmness. Similarly, total yield/plant, was highly significant and positively correlated with average fruit weight, fruit length, TSS (\%) and fruit firmness. Hence, there is ample scope in the improvement of yield by selecting a genotype having higher fruit weight, fruit length, TSS (\%) and fruit firmness since they are highly correlated.

Average fruit weight was significantly or highly significantly positive related with fruit diameter, TSS (\%) and fruit firmness. These results confirmed by Muniappan et al. (2010) and Danquah and Ofori (2012) both for fruit diameter. Finally, there was significant or highly significant positive correlations between fruit length and both of TSS (\%) and fruit firmness. On the other hand, TSS (\%) exhibited significant positive genetic correlation (0.469) with fruit firmness.

\section{Genetic diversity}

Genetic diversity analysis in eggplant could provide useful additional information for studying interrelationships of germplasm and giving graphical assessment of genetic variability, also it helps in breeding vegetables where hybrids derived from distant genotypes exhibit hybrid vigour than those between closely genotypes.

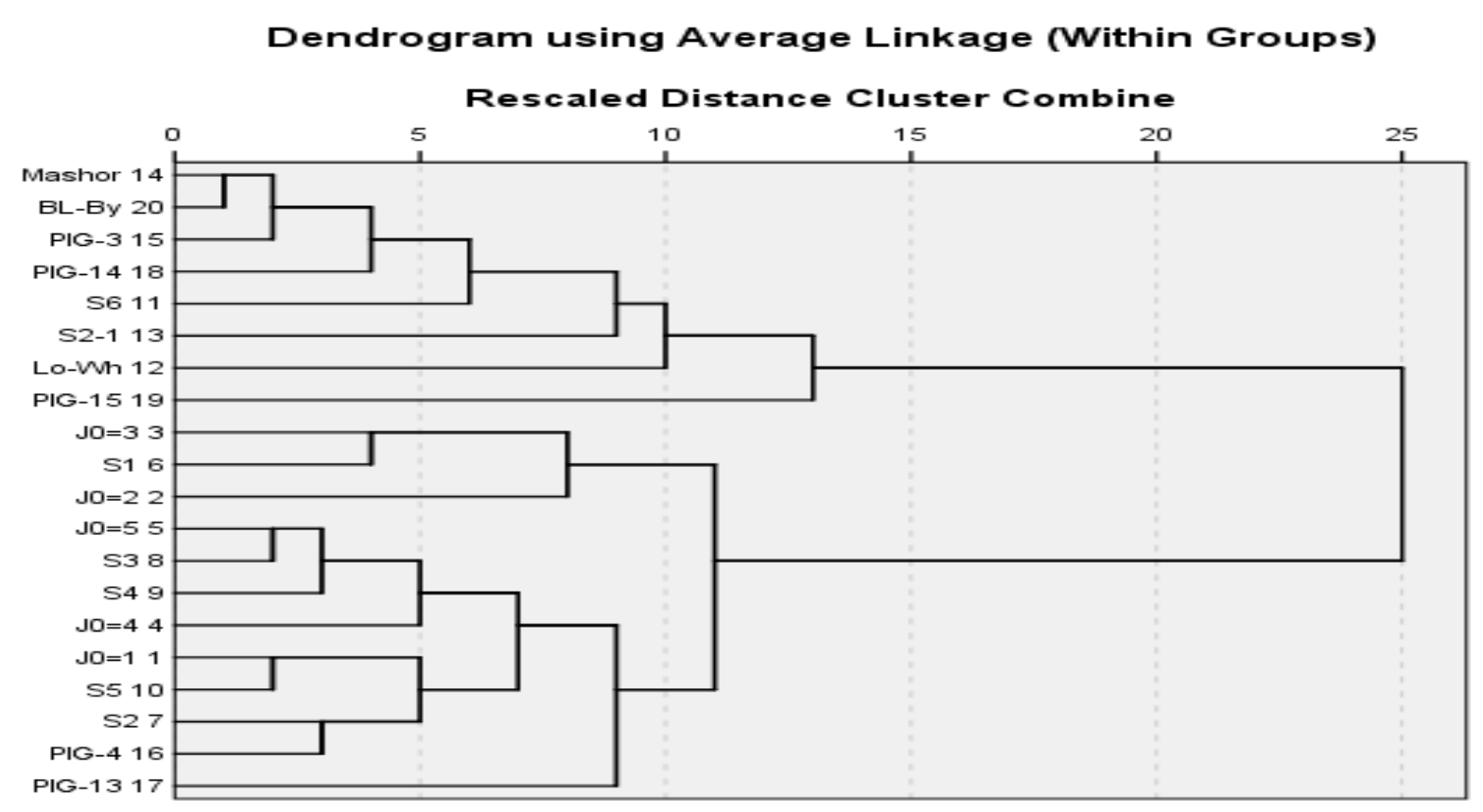

Fig. 1. Dendrogram represent of twenty genotypes of eggplant. 
The genetic divergence based on Euclidean distance among twenty genotypes of eggplant are illustrated in Table 4, for vegetative traits, early and total yield/plant and fruit characteristics to identifying optimal breeding strategies for eggplant improvement. The coefficients were ranged from 3.72 (between Mashor and BL-B) to 37.20 (between Spa-2 and Spa-6), indicating that the genotypes Spa-2 and Spa-6 appeared to be widely divergent (37.20) than other genotypes. On the other hand, the genotypes (Mashor, BL-B, PIG-3, PIG-14 and Spa-6), (Jor-3, Spa-1 and Jor-2) (Jor-5, Spa-3, Spa-4, Jor-4, Jor-1, Spa-5, Spa-2 and PIG4) appeared to be nearly related, respectively also, S2-1, L-W, PIG15 and PIG-13 seemed to be divergent among them. Similar results were reported by Begum et al. (2013), Kumar and Arumugam (2013), Ullah et al. (2014), Yadav et al. (2017), Ravali et al. (2017) and Nand et al. (2018) who studied genetic diversity in genotypes of eggplant for qualitative and quantitative traits and grouped to different clusters based on $\mathrm{D}^{2}$ values.

On the basis of Euclidean distance, the twenty studied genotypes were grouped into five divergent clusters at 10 Euclidean distances (Table 5 and Fig. 1), indicating genetic diversity among genotypes to select the best lines which can be used for any breeding program. The pattern of distribution of genotypes showed that cluster 5 involved the largest number (Jor5, Spa-3, Spa-4, Jor-4, Jor-1, Spa-5, Spa-2, PIG4 and PIG-13), followed by cluster 1 which consisted of six lines (Mas q'1a'hor, BL-B, PIG-3, PIG-14, Spa-6 and S2-1) and cluster 4 which included three lines (Jor-3, Spa-1 and Jor-2). However, both clusters 2 and 3 involved one genotype (L-W and PIG-15, respectively), indicating that genotypes consisted these clusters were relatively closer to each other, in compare to genotypes in other clusters, thus, hybridization between wide divers clusters is important to produce hybrids with high yielding and fruit quality.
Cluster means of the contributed traits revealed the distribution of traits in different clusters (Table 5). Genotypes in cluster 1 gave high performance for only fruit firmness $\left(3.74 \mathrm{~kg} / \mathrm{cm}^{2}\right)$. Cluster 2 included L-W recorded the highest mean values for each of total yield/plant $(1.91 \mathrm{~kg})$, fruit length $(23.67 \mathrm{~cm})$ and TSS (\%) (7.0), therefore, L-W genotype could be used for improvement of total yield/plant and some fruit characters. Also, cluster 3 consisted of PIG-15 genotype and produced the highest mean value for each of plant height (121.67), early yield $/$ plant $(0.220 \mathrm{~kg})$, average fruit weight $(124.67 \mathrm{~g})$ and fruit diameter $(12.83 \mathrm{~cm})$, so, this line is effective in any breeding program for developing these traits. However, cluster 4 exhibited maximum values for number of branches/ plant (6.33) and days to first flower anthesis (30.89). On the other hand, cluster 5 did not give high performance in any trait in spite of included the largest number of genotypes. In general, more emphasis should be given on clusters 1, 2, 3 and 4 for choosing parents for crossing which may produce new recombinants with desired economic traits.

\section{Breeding strategy}

Generally, from the present investigation it may be concluded that, PIG-4 was the best line for early and total yield /plant and exceeded significantly the check hybrid (Classic $\mathrm{F}_{1}$ ) and could be used in eggplant breeding program to increase productivity. The phenotypic selection is more effective and suitable as breeding method for improvement of most studied traits where the genetic variance contributed with large portion in phenotypic. Also, additive gene action plays the main role in the inheritance of studied characters and improvement through selection is effective. However, genetic divergence of twenty genotypes based on Euclidean distance were grouped into five divergent clusters, therefore, the lines belonging to most divergent clusters are predicted to give high heterosis and wide genetic variability. 
Table 4. Euclidean distance among the twenty genotypic of eggplant Proximity Matri.

\begin{tabular}{|c|c|c|c|c|c|c|c|c|c|c|c|c|c|c|c|c|c|c|c|c|}
\hline \multirow[b]{2}{*}{ Case } & \multicolumn{20}{|c|}{ Euclidean Distance } \\
\hline & 1:Jor-1 & 2: Jor-2 & 3:Jor-3 & 4: Jor-4 & 5: Jor-5 & 6: Spa-1 & 7: Spa-2 & 8:Spa-3 & 9:Spa-4 & $\begin{array}{c}\text { 10: } \\
\text { Spa-5 }\end{array}$ & $\begin{array}{c}\text { 11: } \\
\text { Spa-6 }\end{array}$ & $\begin{array}{c}\text { 12: } \\
\text { L-W }\end{array}$ & $\begin{array}{c}\text { 13: } \\
\text { S2-1 }\end{array}$ & $\begin{array}{c}\text { 14: } \\
\text { Mashor }\end{array}$ & $\begin{array}{c}\text { 15: } \\
\text { PIG-3 }\end{array}$ & $\begin{array}{c}\text { 16: } \\
\text { PIG-4 }\end{array}$ & $\begin{array}{c}\text { 17: } \\
\text { PIG-13 }\end{array}$ & $\begin{array}{c}\text { 18: } \\
\text { PIG-14 }\end{array}$ & $\begin{array}{c}\text { 19: } \\
\text { PIG-15 }\end{array}$ & $\begin{array}{c}\text { 20: } \\
\text { BL-B }\end{array}$ \\
\hline 1: Jor-1 & .000 & 9.431 & 6.783 & 7.622 & 8.464 & 7.643 & 9.826 & 9.132 & 6.459 & 4.292 & $28.64 * *$ & 13.182 & 14.810 & $21.66^{* * *}$ & $20.41 \% *$ & 7.420 & 9.584 & $25.45 * *$ & $24.94 * *$ & $23.05 * *$ \\
\hline 2: Jor-2 & & .000 & 6.700 & 15.027 & 14.666 & 11.328 & 13.717 & 13.582 & 11.296 & 9.159 & $26.20 * *$ & 13.512 & 14.347 & $19.09 * *$ & $19.64 * *$ & 12.141 & 13.826 & $24.58 * *$ & $24.53^{* * *}$ & $21.19 * *$ \\
\hline 3: Jor-3 & & & .000 & 10.596 & 11.102 & 5.555 & 13.086 & 10.426 & 7.872 & 8.734 & $25.68^{* * *}$ & 13.002 & 12.213 & $18.60 * *$ & $18.40^{* * *}$ & 12.150 & 11.142 & $24.18 * *$ & $21.14^{* * *}$ & $20.71^{* * *}$ \\
\hline 4: Jor-4 & & & & .000 & 4.793 & 7.705 & 9.754 & 7.483 & 8.444 & 9.093 & $32.78 * *$ & $18.88 * *$ & $18.71^{* *}$ & $26.28 * *$ & $24.99 \div *$ & 10.539 & 12.337 & $30.31 * *$ & $27.18^{* * *}$ & $27.51 \% *$ \\
\hline 5: Jor-5 & & & & & .000 & 9.236 & 6370 & 4.286 & 6.259 & 8.591 & $35.43 * *$ & $20.96 * *$ & $21.19 * *$ & $28.55^{* *}$ & $27.47 * *$ & 8.406 & 13.280 & $32.91 * *$ & $29.83^{* * *}$ & $30.12 * *$ \\
\hline 6:Spa-1 & & & & & & .000 & 12.829 & 8.883 & 7.922 & 9.511 & $26.92 * *$ & 14.715 & 12.831 & $20.19 * *$ & $19.51 * *$ & 12.661 & 9.331 & $25.42 * *$ & $21.06^{* * *}$ & $21.95 * *$ \\
\hline 7:Spa-2 & & & & & & & .000 & 6.059 & 8.036 & 7.116 & $37.20 * *$ & $22.17^{* * *}$ & $23.10 * *$ & $30.06^{* * *}$ & $2935^{* *}$ & 4.790 & 14.001 & $34.44 * *$ & $33.03 * *$ & $31.64 * *$ \\
\hline 8:Spa-3 & & & & & & & & .000 & 4.850 & 8.207 & $34.96 * *$ & $21.13 * *$ & $20.49 * *$ & $27.80^{* * *}$ & $27.19 \div *$ & 8.267 & 11.459 & $32.88 * *$ & $28.97 * *$ & $29.69 * *$ \\
\hline 9:Spa-4 & & & & & & & & & .000 & 6.832 & $32.21 * *$ & 17.772 & 18.049 & $24.94 * *$ & $24.04 * *$ & 7.598 & 10.121 & $29.62 * *$ & $26.65^{* * *}$ & $26.89 * *$ \\
\hline 10:Spa-5 & & & & & & & & & & .000 & $30.65^{* *}$ & 15.362 & 16.775 & $23.54 * *$ & $22.69 * *$ & 4.343 & 9.347 & $27.56 * *$ & $27.49 * *$ & $24.95 * *$ \\
\hline 11:Spa-6 & & & & & & & & & & & .000 & 16.992 & 14.715 & 7.652 & 9.263 & $34.65^{* * *}$ & $27.29 * *$ & 8.124 & 13.28 & 6.005 \\
\hline 12: $\mathrm{L}-\mathrm{W}$ & & & & & & & & & & & & .000 & 7.977 & 10.874 & 8.568 & $18.87^{* * *}$ & 14.562 & 12.527 & 18.09 & 11.339 \\
\hline 13:S2-1 & & & & & & & & & & & & & .000 & 8.021 & 7.900 & $20.88^{* * *}$ & 13.158 & 13.830 & 12.038 & 9.567 \\
\hline 14: Mashor & & & & & & & & & & & & & & .000 & 4.827 & $27.51^{* * *}$ & $20.32 * *$ & 8.720 & 11.368 & 3.715 \\
\hline 15: PIG-3 & & & & & & & & & & & & & & & .000 & $26.47 * * *$ & $1936^{* * *}$ & 6.413 & 12.048 & 4.429 \\
\hline 16:PIG-4 & & & & & & & & & & & & & & & & .000 & 11.987 & $31.17 * *$ & $31.39 * *$ & $28.92 * *$ \\
\hline 17:PIG-13 & & & & & & & & & & & & & & & & & .000 & $24.60 * * *$ & $22.28 * *$ & $21.78^{* *}$ \\
\hline 18: PIG-14 & & & & & & & & & & & & & & & & & & .000 & 16.377 & 6.086 \\
\hline 19: PIG-15 & & & & & & & & & & & & & & & & & & & .000 & 12.723 \\
\hline 20: BL-B & & & & & & & & & & & & & & & & & & & & .000 \\
\hline
\end{tabular}

* Significant compared with $\mathrm{X}^{2}=18.31$ at $\mathrm{df}=10$ and 0.05 level of probability 
Table 5. Distribution of parents into clusters and cluster means of the contributed characters.

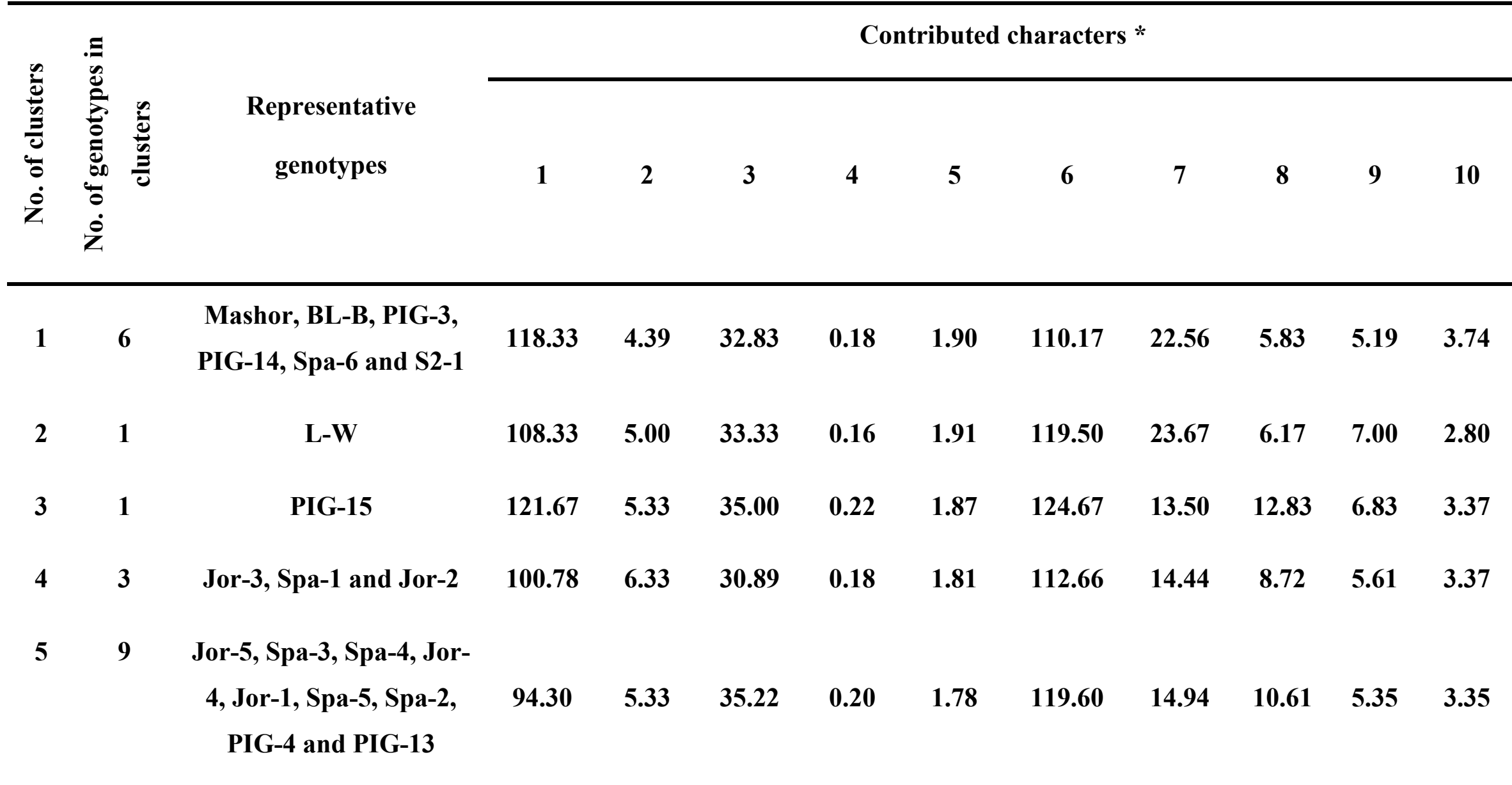

\footnotetext{
* 1- Plant highte 2- No. of branches 3- days to first flower anthesis 4- early yield 5- total yield

6- average fruit wight 7 - fruit length 8 - fruit diameter $\quad 9$ - TSS (\%) 10 - Fruit firmness $\left(\mathrm{kg} / \mathrm{cm}^{2}\right)$
} 


\section{REFERENCES}

Allard, R.W. (1960). Principles of Plant Breeding. John Willey and Sons. Inc. London, 83-108.

Ansari, S.F., Mehta, N.; Ansari, S. and Gavel, J.P. (2011). Variability studies in Brinjal (Solanum melongena L.) in Chhattisgarh plains. Electronic J. Plant Breed., 2 (2): 275-281.

Begum, F.; AminulIslam, A.K.M.; Rasul, G.M.; Mian, K.M.A. and Hossain, M.M. (2013). Morphological diversity of eggplant (Solanum melongena) in Bangladesh. Emirates J. Food and Agric., 25 (1): 45-51.

Burton, G.W. and Devane, E.H. (1953). Estimating heritability in tall fescue (Festuca arundinaceae) from replicated clonal material. Agro. J., 45: 478-481.

Cochran, W.G. and Cox, G.M. (1957). Experimental Designs. $2^{\text {nd }}$ Ed., John Willey and Sons, New York, USA. 611.

Danquah, J.A. and Ofori, K. (2012). Variation and correlation among agronomic traits in 10 accesssions of garden eggplant (Solanum gilo Raddi) in Ghana, Int. J. Scie. and Nat., 3 (2): 373-379.

Duncan, B.D. (1955). Multiple Range and Multiple F test. Biomet., 11: 1-42.

Islam, M.S. and Uddin, M.S. (2009). Genetic variation and trait relationship in the exotic and local eggplant germplasm. Bangladesh J. Agric. Res., 34 (1): 91-96.

Johnson, H.W.; Robinson, H.F. and Comstock, R.E. (1955). Estimates of genetic and environmental variability in soybean. Agron. J., 47(7): 314-318.

Kansouh, A.M. and Hussein, A.H. (2009). Developing lines of eggplant (Solanum melongena L.) by selection. Egypt. J. Appl. Sci., 24 (12B): 650-665.

Kowalski, R.; Kowalski, G. and Wiercinski, J. (2003). Chemical composition of fruits of three eggplant (Solanum melongena L.) cultivars. Folia Hort., 15 (2): 89-95.

Kumar, R.S. and Arumugam, T. (2013). Phenotypic evaluation of indigenous Brinjal types suitable for rainfed conditions of South India, Afr. J. Biotech., 12 (27): 4338-4342.

Kumar, R.S.; Arumugam, T.; Anandakumar, C.R. and Rajavel, D.S. (2012). Estimation of heterosis and specific combining ability for yield, quality, pest and disease incidence in eggplant (Solanum melongena L.), Bull. Environ., Pharm. and Life Sci., 2 (1):0315.

Mahalanobis, P.C. (1936). On the Generalized Distance in Statistics. Proc. Nat. Inst. Sci. India, 2, 49-55.

Muniappan, S.; Saravanan, K. and Ramya, B. (2010). Studies on genetic divergence and variability for certain economic characters in eggplant (Solanum melongena L.). Electronic J. Plant Breed., 1 (4): 462-465

Nair, R. and Mehta, A.K. (2007). Correlation and path coefficient analysis for some metric traits in brinjal (Solanum melongena L.). Asian J. Hort., 2 (2): 164-168.

Nand, N.; Adarsh, A.; Kumar, A.; Akhtar, S.; Kumar, R. and Ray, P.K. (2018). Morphological characterization of different genotype of brinjal (Solanum melongena). Int. J. Current Microbi. and Appl. Sci.,7 (1): 2218-2226.

Prabakaran, S.; Balakrishnan, S.; Kumar, R.S.; Arumugam, T. and Anand Akumar, C.R. (2015). Genetic diversity, trait relationship and path analysis in eggplant landraces. Electronic J. Plant Breed., 6 (3):831-837.

Pujer, P.; Jagadeesha, R.C. and Cholin, S. (2017). Genetic variability, heritability and genetic advance for yield, yield related components of brinjal (Solanum 
melongena L.) Genotypes, Int. J. puree and appl. Biosci., 5 (5): 872-878.

Rad, M.R.N.; Poodineh, M.; Ghalandarzehi, A. and Abkhoo, J. (2015). Variability, heritability and association analysis in eggplant (Solanum melongena), ARPN J. Agric. Biol. Sci., 10 (12): 464-468.

Ravali, B.; Reddy, R.K.; Saidaiah, P. and Shivraj, N. (2017). Genetic diversity in brinjal (Solanum melongena L.). Int. J. Current Microbi. and Appl. Sci., 6 (6): 48-54.

Samlindsujin, G.; Karuppaiah, P. and Manivannan, K. (2017). Genetic variability and correlation studies in brinjal (Solanum melongena L.). Int. j. Plant Sci., 12 (1): 21-27.

Shekar, C.K.; Ashok, P.; HariKumar, V. and RaviKumar, K. (2014). Correlation, path analysis and genetic divergence in brinjal (Solanum melongena L.). Plant Archives, 14 (2): 893-898.

Shende, K.G.; Birajdar, U.M.; Bhalekar, M.N. and Patil, B.T. (2014). Correlation and path analysis in eggplant (Solanum melongena L.). South Indian Hort. J., 39 (1): 108-110.

Steel, R.G. and Torrie, H.H. (1980). Principals and Procedures of Statistics.
Mc Graw-Hill Book Co. Inc. New York. 481.

Tripathy, B.; Sharma, D.; Jangde, B.P. and Bairwa, P.L. (2018). Evaluation of brinjal (Solanum melongena L.) genotypes for growth and yield characters under Chhattisgarh condition. The Pharma Innovation J., 6 (10): 416-420.

Tirkey, M.; Saravana, S. and Pushpa, L. (2018). Studies on variability, heritability and genetic advance for yield and its attributes in brinjal (Solanum melongena L.). J. Pharm. and Phytochem., 181-1183.

Ullah, S.; Ijaz, U.; Shah, T.I.; Najeebullah, M. and Niaz, S. (2014). Association and genetic assessment in brinjal, European J. Biot. and Biosci., 2(5): 41-45.

Vavilov, N.I. (1951). Origin, variation, immunity and breeding of cultivated plants. Chronol. Bot., 13: 4-364.'

Yadav, N.; Dhankar, S.K.; Chandanshive, A.V. and Kumar, V. (2016). Studies on variability, heritability and genetic advance in brinjal (Solanum melongena L.). The Bioscan., 11 (4): 3001-3005.

Yadav, N.; Dhankar, S.K.; Chandanshive, A.V. and Kumar, V. (2017). Genetic divergence in brinjal (Solanum melongena L.). J. Appl. and Nat. Sci., 9 (2): 1032-1035. 


\section{الملخص العربي \\ تقييم تراكيب وراثية من الباذنجان تحت ظروف شمال سيناء

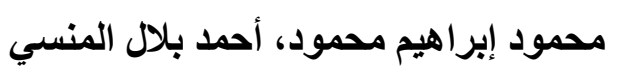

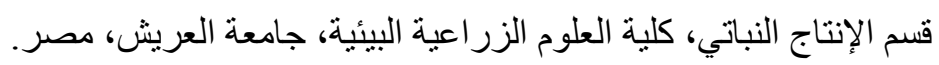

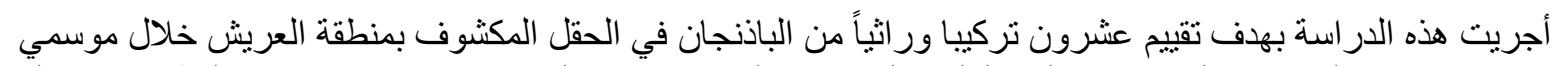

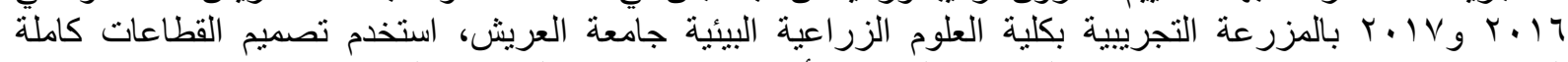

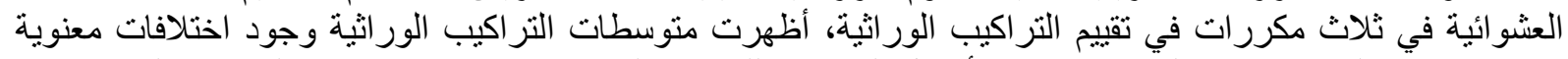

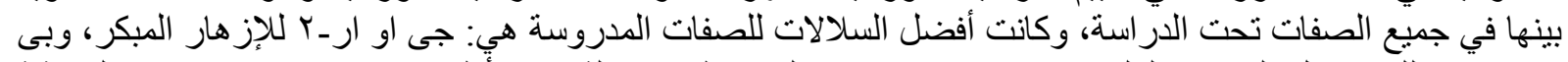

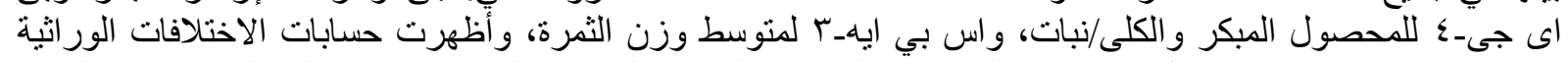

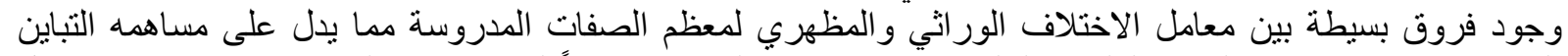

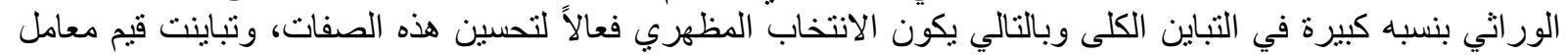

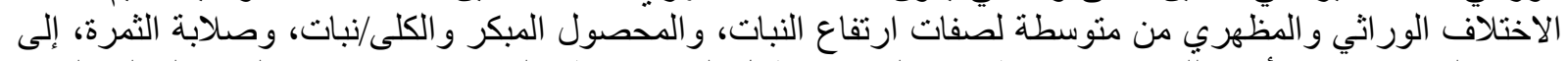

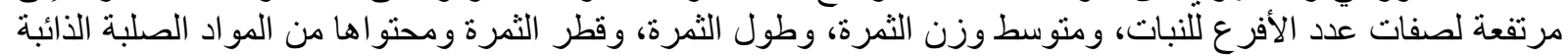

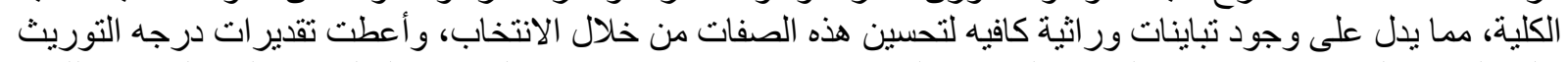

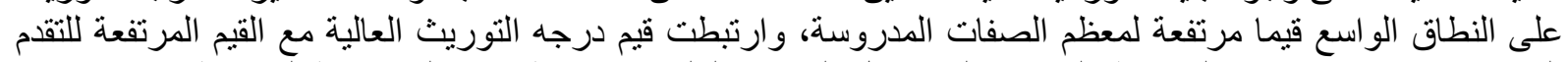

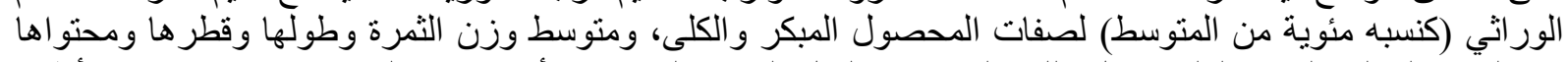

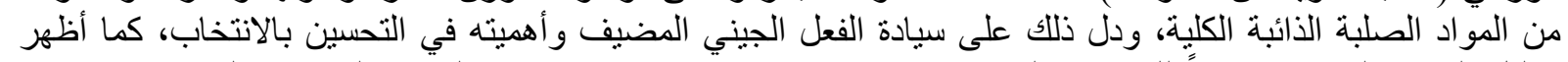

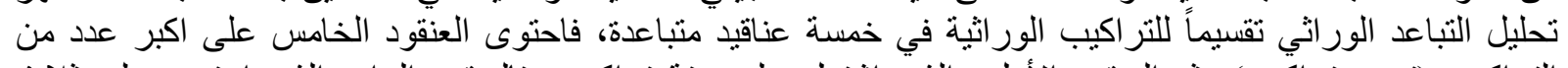

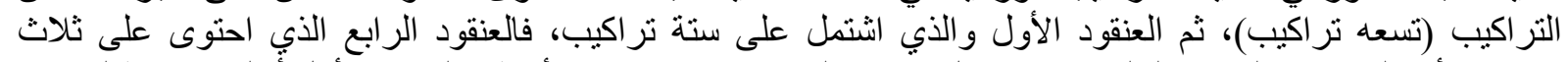

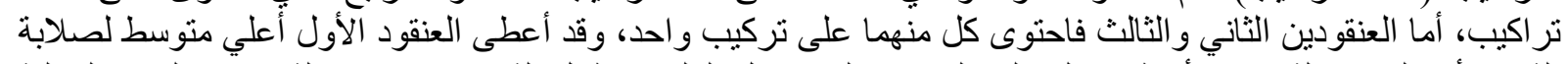

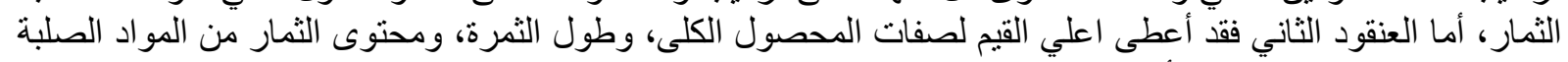

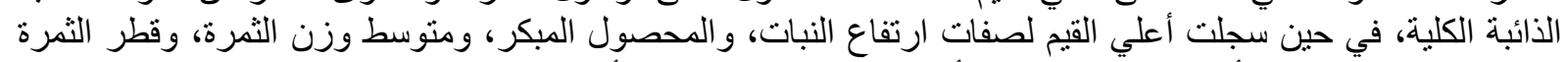

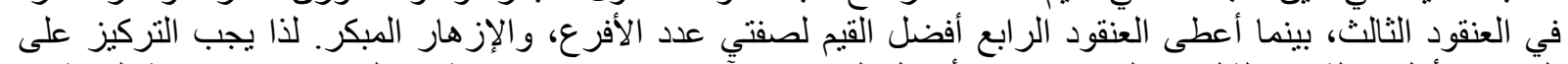

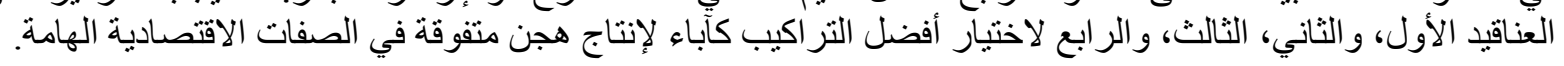

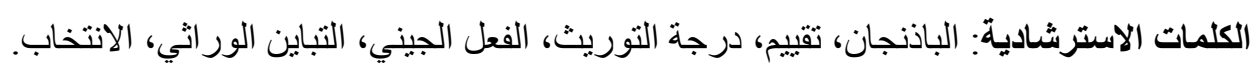

